\title{
Bacillary angiomatosis: A unique cutaneous complication of HIV infection
}

Joan Lipa MD, Walter Peters PhD MD FRCSC, Victor Fornasier MD FRCPC, Benjamin Fisher MD FRCPC

Divisions of Plastic Surgery, Pathology and Dermatology, Wellesley Hospital, University of Toronto, Toronto, Ontario

J Lipa, W Peters, V Fornasier, B Fisher. Bacillary angiomatosis: A unique cutaneous complication of HIV infection. Can J Plast Surg 1995;3(2):96-101. As the prevalence of human immunodeficiency virus (HIV) infection increases, so does the recognition of unusual manifestations of this syndrome. This study describes two patients who presented with a unique, rare, cutaneous manifestion of HIV infection. One patient developed an aggressive atypical cellulitis and ascending lymphangitis of the hand, which failed to improve following multiple courses of several different antibiotics. The other patient presented with multiple, vascular, nodular lesions, clinically resembling Kaposi's sarcoma. Routine biopsies and wound cultures were not helpful for diagnosis. A definitive diagnosis of bacillary angiomatosis (BA) was made using a special silverstaining (Warthin-Starry) histological technique and electron microscopy. Both patients responded completely to oral erythromycin therapy. BA is a newly recognized bacterial infection caused by bacteria of the genus Bartonella. It is seen primarily in patients with acquired immunodeficiency syndrome (AIDS), and less commonly in patients with other immunosuppressed conditions. The term BA describes the lesion's pathogenesis (infective-bacillary) and clinico-histology (angiomatosis). The causal organism cannot be cultured reliably and is resistant to most antibiotics. This study reviews these two patients, the differential diagnosis of BA, specific confirmatory tests used in diagnosis, and the treatment outcome of this condition. It is important for the plastic surgeon to understand BA, because it can resemble other common presentations, but it can also be associated with internal involvement leading to mortality. However, when recognized, it can usually be cured by oral erythromycin therapy (500 mg qid) for several weeks.

Key Words: Bacillary angiomatosis, Bartonella, Human immunodeficiency virus, Immunosuppression

Angiomatose bacillaire : rare complication cutanée d'une infection au VIH

RÉSUMÉ : À mesure que la prévalence du virus de l'immunodéficience humaine (VIH) augmente, on reconnaît un plus grand nombre de manifestations inhabituelles de ce syndrome. Cette étude décrit deux patients qui se sont présentés avec des signes cutanés uniques et rares d'infection au VIH. Un patient a développé une cellulite atypique agressive, une lymphangite ascendante de la main qui ne s'est pas résorbée en dépit de 
plusieurs traitements à l'aide de différents antibiotiques. L'autre patient a présenté des lésions nodulaires vasculaires multiples, ressemblant au sarcome de Kaposi sur le plan clinique. Les biopsies habituelles et les cultures des lésions n'ont pas été utiles pour le diagnostic. Un diagnostic définitif d'angiomatose bacillaire a pu être posé à l'aide d'une technique histologique spéciale colorée à l'argent (Warthin-Starry) et de microscopies électroniques. Les deux patients ont totalement répondu à un traitement oral par érythromycine. L'angiomatose bacillaire est une nouvelle infection bactérienne causée par la bactérie du genre Bartonella. Elle s'observe surtout chez les patients atteints du syndrome d'immunodéficience humaine (SIDA) et moins fréquemment chez des patients souffrant de maladies liées à l'immunosuppression. Le terme d'angiomatose bacillaire décrit la pathogenèse de la lésion (infectieuse-bacillaire) et l'histologie clinique (angiomatose). L'organisme causal ne peut être cultivé de façon fiable et résiste à la plupart des antibiotiques. Cette étude passe en revue ces deux cas, le diagnostic différentiel d'angiomatose bacillaire, les épreuves spécifiques de confirmation utilisées pour le diagnostic et le traitement de la maladie. Il est important pour le plasticien de comprendre l'angiomatose bacillaire, parce qu'elle ressemble à d'autres présentations fréquentes, mais qu'elle peut aussi être associée à une atteinte interne qui conduit au décès. Toutefois, lorsqu'on la reconnaît, elle est habituellement traitée par voie orale avec un schéma d'érythromycine (500 mg q.i.d.) de quelques semaines.

Bacillary angiomatosis (BA) is a relatively uncommon complication of immunosuppression. It has been identified in association with all stages of human immunodeficiency virus (HIV) infection, both prior to seroconversion (1) and in the late stages of acquired immunodeficiency syndrome (AIDS). The average CD4+ cell count at the time of diagnosis is $57 / \mathrm{mm}^{\wedge} 3(2)$. BA has also been seen in transplant patients on immunosuppressive therapy (3), in patients with disseminated malignancy $(4,5)$, and has been described rarely in immunocompetent individuals as a localized infection (6).

Stoler first described BA in 1983, as cutaneous lesions which developed in AIDS patients, that resembled Kaposi's sarcoma but resolved with erythromycin (7). The term 'bacillary angiomatosis' was subsequently coined in 1989 by LeBoit (8). This name appropriately described the lesion's pathogenesis (infective-bacillary) and histology (angiomatosis). As the prevalence of HIV infection rises, it becomes increasingly important for the plastic surgeon to recognize and accurately diagnose the cutaneous manifestations of this syndrome.

\section{Case 1}

\section{CASE REPORTS}

A 38-year-old male with a one-year history of HIV infection presented with multiple, tender, red, nodular skin lesions which had been rapidly progressive over a two month period. A representative lesion, located above the patient's right eyebrow, is shown in Figure 1. Similar lesions also appeared on the patient's scalp (Figure 2), thigh, leg and penis. Some of the lesions were eroded. Others were papules or subcutaneous nodules. 


\section{Lipa et al}

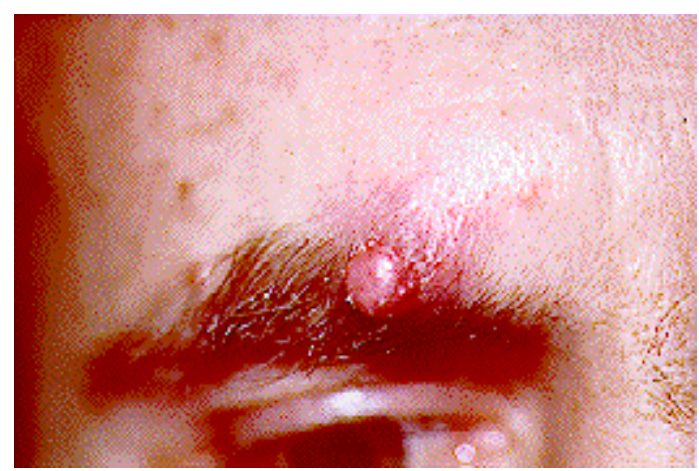

Figure 1) Case 1: Tender, erythematous nodule above right eyebrow of 38-year-old HIV positive male

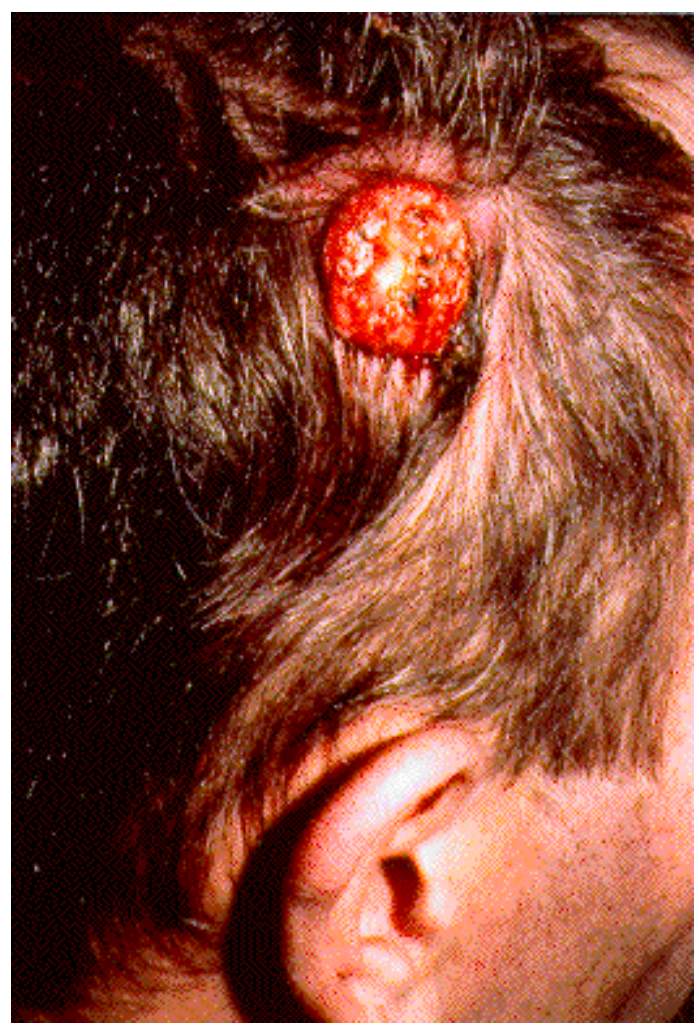

Figure 2) Case 1: Nodule on scalp resembling a pyogenic granuloma

\section{Bacillary angiomatosis}

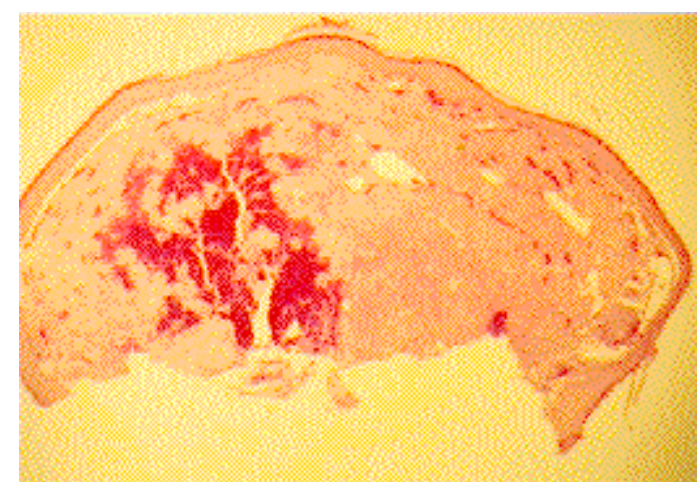

Figure 3) Case 1: Hematoxylin and eosin stain of nodule from right eyebrow. Low magnification shows nodular structure with extensive cellularity in dermis and normal epidermis, and with dilated, large, bloodfilled capillaries (original magnification $x$ 12.5)

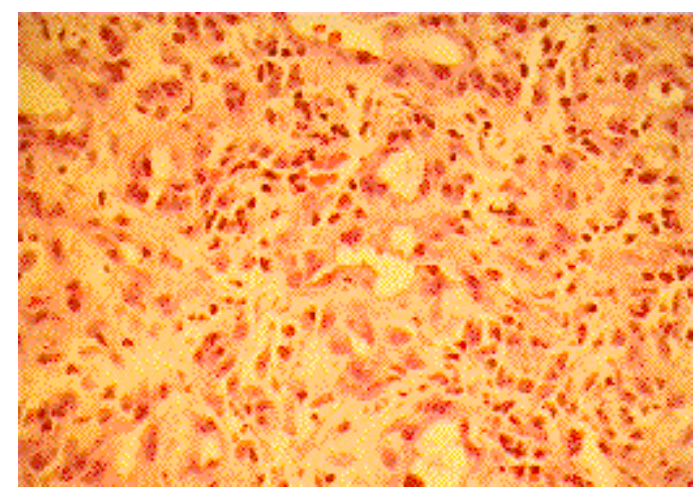

Figure 4) Case 1: Higher magnification of Figure 3 shows vascular proliferation, with cuboidal endothelial cells, inflammatory exudate, and granular material (hematoxylin and eosin, original magnification $\times 250$ ).

The patient's CD4+ cell count was $170 / \mathrm{mm}^{3}$. His AIDS-related illnesses had included cryptococcal meningitis, Pneumocystis carinii pneumonia, oral candidiasis, and perianal herpes simplex virus erosions. His medications consisted of AZT, acyclovir, pentamidine, 
trimethoprim, fluconazole, dapsone and cephalexin (a first-generation cephalosporin). Despite these antivirals, antiobiotics and antifungals, as well as a previously attempted ablative therapy with topical liquid nitrogen, the lesions had continued to increase rapidly in size.

The differential diagnosis included pyogenic granuloma, keratoacanthoma, and Kaposi's sarcoma. In an attempt to obtain a definitive diagnosis, a biopsy of the right eyebrow lesion was performed under local anaesthetic. The hematoxylin and eosin (H\&E) slide was initially reported by the pathologist as 'inflamed granulation tissue' with no evidence of malignancy. Low magnification showed the nodular structure, with extensive cellularity in the dermis (Figure 3). Higher magnification showed vascular proliferation, cuboidal endothelial cells, inflammatory exudate and granular material (Figure 4).

The patient subsequently developed a new nodule on his right arm, and was seen by a dermatologist (BF) who suspected a clinical diagnosis of BA. A Warthin-Starry silver-stain histopathological study of the arm nodule confirmed a diagnosis of BA (Figure 5). This showed pleomorphic Bartonella bacilli in clumps. Transmission electron microscopy showed numerous, extracellular, bacillary forms with characteristic trilaminar cell wall and electron dense granular central structures (Figure 6).

\section{Case 2}

A 39-year-old male had been diagnosed HIV-positive nine years previously. $\mathrm{He}$ had been free from AIDS-defining illnesses (having only persistent generalized lymphadenopathy), and had maintained a $\mathrm{CD} 4^{+}$cell count of $250 / \mathrm{mm}^{3}$. He was referred for evaluation of a tender abscess that had spontaneously ruptured, proximal to the nail fold of his right dominant ring finger (Figure 7). There was no history of trauma. A clinical diagnosis of paronychia was made, and the patient was given a 12-day course of oral cloxacillin. He failed to respond, and developed tender erythematous nodules extending proximally to the dorsum of his hand and lower forearm (Figure 8). It was thought that this could represent a form of ascending lymphangitis, due to an atypical streptococcal infection. A course of oral penicillin and clindamycin was initiated. Worsening of symptoms, with increased hand edema and consequent acute compression neuropathies, ensued over the next week, necessitating hospital admission for elevation, splinting, and broad spectrum intravenous antibiotic coverage with penicillin, clindamycin, and gentamicin. This atypical hand infection failed to improve. An Infectious Diseases consultation suggested a clinical diagnosis of BA. Erythromycin 500 $\mathrm{mg}$ intravenously q6h was started. There was dramatic improvement over the next $48 \mathrm{~h}$, with shrinking of the nodules and resolution of the associated erythema and edema. Erythromycin was subsequently given orally for eight weeks. The lesions healed completely, with slight discolouration of the sites. 


\section{PERSONA USE ONIY - DO NOT COPY}

\section{Lipa et al}

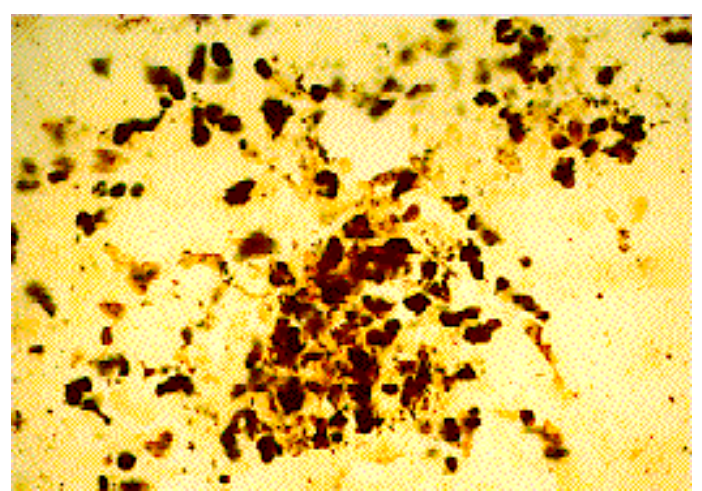

Figure 5) The Warthin-Starry stain shows the pleomorphic Rochalimaea bacilli in clumps, which correspond to the granular material seen previously on the hematoxylin and eosin stain in Figure 4. (Warthin-Starry stain, original magnification $x$ 250)

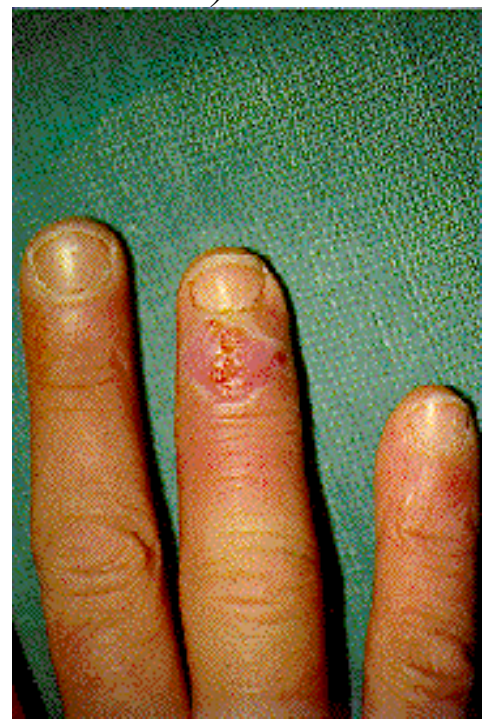

Figure 7) Case 2: Ruptured atypical 'paronychia' on ring finger of 39-year-old HIV positive male

\section{Bacillary angiomatosis}

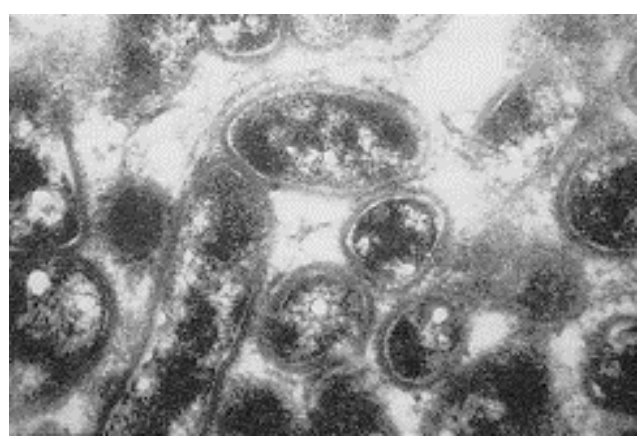

Figure 6) Transmission electron micrograph reveals numerous extracellular bacillary forms with characteristic trilaminar cell wall and electron dense granular central structures (electron microscopy, original magnification $x$ 90,000)

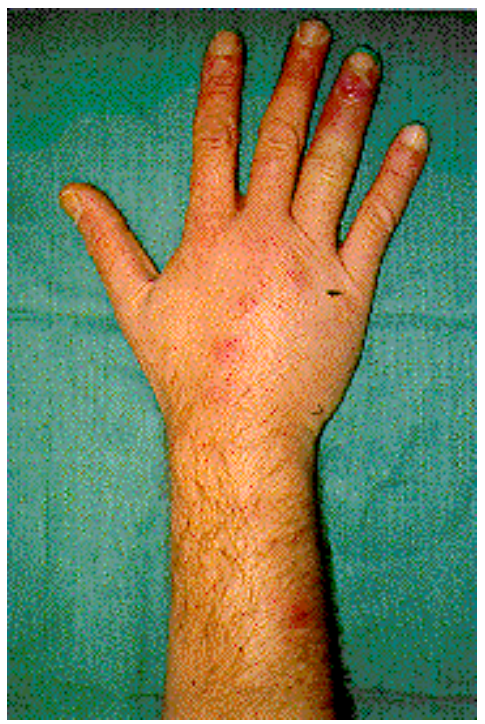

Figure 8) Case 2: Progression of 'paronychia' with tender erythematous nodules extending from the dorsum of the hand to the lower forearm, resembling an atypical cellulitis/ascending lymphangitis

\section{DISCUSSION}

Etiology: The unique vascular lesion of BA is caused by a small, weakly Gram-negative bacillus of the genus Bartonella. Originally, the organism remained elusive, and it was presumed that BA was caused by the same organism that caused cat-scratch disease (CSD) (9). It was postulated that the CSD bacillus incited a granulomatous disease in the immunocompetent host, but manifested itself as a disseminated infection with vascular lesions in the immunodeficient host (8). BA was also noted to have clinical and histologic similarities to verruga peruana, the late manifestation of Bartonella bacilliformis 
infection. It was thought that the causative agent of BA may be related to $B$ bacilliformis (10). Subsequent molecular and microbiological investigations indicated that the etiological bacilli of BA were of the genus Rochalimaea, in the Rickettsiaceae family (11). Most recently, however, the causative organisms have been reclassified to the genus Bartonella as $B$ henselae and B quintana (12). The CSD bacillus has been identified as Afipia felis (13).

Presentation: Bartonella infections can affect virtually any organ system, either singly or multiply (2). Although cutaneous involvement is the most frequently recognized manifestation, there may also be more serious parenchymal involvement. Concurrent organ involvement must be excluded, as this can impact on morbidity and duration of therapy. Bartonella osteomyelitis presents with painful osteolytic lesions usually in long bones, occasionally with overlying soft tissue masses or erythematous cellulitic dermal plaques. Bone scans with ${ }^{\wedge} 99 \mathrm{~m}$ Technetium methylene diphosphonate are positive (14). Hepatic involvement results in a condition termed peliosis hepatis. This consists of unique vascular lesions associated with the BA bacillus that can be seen on ultrasound or computerized tomographic (CT) scan. Hepatic transaminases can be normal or only mildly elevated, but alkaline phosphatase is often markedly elevated, up to five times normal (15). Bacteremia can occur in the absence of localized tissue infection (16) and presents with fever, chills and weight loss. Blood cultures are positive only if strict guidelines for culture are followed (17). Rarely, there can also be involvement of the gastrointestinal tract, respiratory system, lymphatic system, central nervous system, bone marrow, endocardium and venous systems (with thrombosis) (2).

Cutaneous lesions are usually vascular and tender. There are three distinct morphologic entities which have been classified by Webster (1): pyogenic granulomalike (Figures 1,2), subcutaneous nodular (Figure 7), and hyperpigmented indurated plaques. Pyogenic granuloma-like lesions range in size from $0.1 \mathrm{~cm}$ to several centimetres in diameter. They are dusky red with a fine, tightly adherent scale. They are firm but friable and may bleed when traumatized. They have been described as tracking linearly along forearm veins (18). Subcutaneous nodular lesions (Figure 7) may appear as vigorous outgrowths or may require palpation for detection. There is often no clinical evidence of epidermal change, or there may be minimal hyperpigmentation. The third, less common form, the hyperpigmented indurated plaques, occur on people with darkly pigmented skin and are often ovoid, hyperkeratotic, and with indistinct borders. Our first patient also showed a papular skin-coloured lesion on the penis and a furuncle-like lesion on the right knee.

Diagnosis: The clinical appearance of cutaneous BA is often distinctive and may facilitate a presumptive diagnosis (19). A definitive diagnosis is best made histopathologically (2). Routine H\&E staining reveals distinctive characteristics. There is vascular proliferation of capillary-sized blood vessels lined with protuberant, cuboidal or polygonal endothelial cells with abundant cytoplasm, with or without cytological atypia (Figures 3 and 4). An inflammatory infiltrate with numerous neutrophils is present and there may be areas of focal necrosis. Granular or fibrillary amorphic material is present extracellularly throughout the connective tissue in close proximity to vascular channels (8). Subcutaneous lesions, in contrast to the pyogenic granuloma-like lesions, often have 
a compact stroma which is more dense and cellular (2). Stains for fungi or acid-fast mycobacteria and Brown-Brenn tissue Gram stains are negative.

Diagnostic confirmation may be achieved with silver staining, such as WarthinStarry, Steiner's or Dieterle's silver stains (8). This reveals numerous pleomorphic bacilli which correspond to the granular material seen on H\&E stains (Figure 5).

Silver stains must be performed under low $\mathrm{pH}$ conditions. Even when BA organisms are present, these stains are not always positive. Electron microscopy is thus essential, if there is a question of diagnosis. Electron microscopy (Figure 6) demonstrates the characteristic trilaminar cell-walled bacilli which are 0.2 to $0.5 \mu \mathrm{m}$ by 1.0 to $3.0 \mu \mathrm{m}$ in size (9).

Other diagnostic modalities are less practical, but have been used for research purposes. These include immunocytochemical staining (20), serology with immunofluorescent antibody (IFA) testing (21) and enzyme immunoassay (EIA) (22), polymerase chain reaction techniques for the detection of Bartonella DNA (23), and blood cultures which are difficult since the BA organism is fastidious, requiring at least three weeks to grow under very specific conditions (17).

Differential diagnosis: The differential diagnosis includes both noninfectious and infectious lesions. The vascular malignancy, Kaposi's sarcoma, which frequently afflicts AIDS patients, can be easily confused with cutaneous BA (Figures 1,2). Kaposi's sarcoma lesions, however, evolve from patches to plaques to nodules. BA lesions begin as minute papules which become larger. As well, the two entities may be differentiated histologically. Kaposi's sarcoma endothelial cells are characteristically spindle-shaped, in contrast to the endothelial cells of BA, which are cuboidal (19). Pyogenic granuloma can also be differentiated histologically from BA. Pyogenic granuloma usually contain a paucity of neutrophils, more lymphocytes, and no bacteria, compared to BA (8). Other benign lesions may resemble BA clinically, such as dermatofibroma, angiokeratoma and cherry angioma (2). Infectious lesions included in the differential are verruga peruana ( $B$ bacilliformis) lesions, but these have only been found in South America. Other mycobacterial and fungal cutaneous lesions may also resemble BA: Mycobacterium kansasii, Mycobacterium marinum, Coccidioides immitis, Cryptococcus neoformans, Histoplasma captulatum and Sporothrix schenckii (24).

Treatment: Although therapy for BA has never been systematically studied, since 1983 erythromycin has been the mainstay of treatment. Empirical therapy with erythromycin $500 \mathrm{mg}$ po qid (25) results in improvement in cutaneous lesions within one week, and resolution within one month, leaving hyperpigmentation indefinitely (26). For severe infections, or when gastrointestinal side effects precludes oral erythromycin, the intravenous form has been advocated (2). There have been no reported cases resistant to erythromycin (1). Other antibiotics have been used with variable success (2). There is no response to penicillins, penicillinase-resistant penicillins, or first-generation cephalosporins (25). This is significant since these latter antibiotics are often the mainstay of therapy for infections seen commonly by the plastic surgeon. As well, there is no response to either radiation or cytotoxic therapy which are used to treat Kaposi's sarcoma (1). 
The duration of therapy is determined by concurrent organ involvement (2). Isolated cutaneous BA may be cured with an eight-week course of erythromycin, $2 \mathrm{~g} /$ day. However, relapse may occur, requiring an additional 16-week course, and osseous and hepatic disease may require lifelong suppressive therapy. Although untreated lesions may occasionally resolve or persist without spread, most increase in size and number resulting in significant disfiguration (1). It is imperative that BA be treated since there have been two reported cases of death as a result of concurrent systemic disease (27).

Epidemiology: Anecdotal reports initially linked BA to traumatic exposure to cats. Recently, a systematic investigation between environmental exposure and BA was conducted (28). This large case-control study showed an association between the development of BA and a recent cat bite or scratch. There was no association with insect bites, even though other members of the family Rickettsiaceae are transmitted via arthropod vectors. It is interesting to note that one-third of the patients with BA had no exposure to cats. This was explained by the possibility that $B$ henselae and $B$ quintana, both of which cause BA, may have different modes of transmission, so the risk factors for acquisition of the two organisms may differ.

\section{CONCLUSION}

BA is a unique, AIDS-related disorder which is novel, since it is caused by a bacteria, rather than the virus or fungus which usually afflicts AIDS patients. The implication is that the natural defense mechanism to the organism must be T-cell mediated. Recognition of cutaneous BA is important since Bartonella infection is potentially fatal due to concurrent organ involvement. As well, the lesions can be easily confused with other malignant, benign or infectious processes which the plastic surgeon encounters frequently. When recognized, BA is usually easily treated and cured with erythromycin.

\section{REFERENCES}

1. Webster GF, Cockerell, CJ, Friedman-Kien AE. The clinical spectrum of bacillary angiomatosis. Br J Dermatol 1991;126:535-41.

2. Koehler JE, Tappero JW. Bacillary angiomatosis and bacillary peliosis in patients infected with human immunodeficiency virus. Clin Infect Dis 1993;17:612-24.

3. Kemper CA, Lombard CM, Deresinski SC, et al. Visceral bacillary epithelioid angiomatosis: possible manifestations of disseminated cat scratch disease in the immunocompromised host: a report of two cases. Am J Med 190;89:216-22.

4. Pembroke AC, Grice K, Levantine AV, Warin AP. Eruptive angiomata in malignant disease. Clin Exp Dermatol 1978;3:147-56.

5. Omura EF, Omura GA. Human immunodeficiency virus-associated skin lesions. JAMA 1989;261:991.

6. Cockerell CJ, Bergstresser PR, Myrie-Williams C, et al. Bacillary epithelioid angiomatosis occurring in an immunocompetent individual. Arch Dermatol 1990;126:787-90.

7. Stoler MH, Bonfiglio TA, Steigbigel RT, et al. An atypical subcutaneous infection associated with acquired immune deficiency syndrome. Am J Clin Pathol 1983;80:714-8. 
8. LeBoit PE, Berger TG, Egbert BM, et al, Bacillary angiomatosis. The histopathology and differential diagnosis of apseudoneoplastic infection in patients with human immunodeficiency virus disease. Am J Surg Pathol 1989;13:909-20.

9. LeBoit PE, Berger TG, Egbert BM, et al. Epithelioid hemangioma-like vascular proliferation in AIDS: manifestation of cat scratch disease bacillus infection? Lancet 1988;i:960-3.

10. Garcia FU, Wojta J, Broadley KN, et al. Bartonella bacilliformis stimulates endothelial cells in vitro and is angiogenic in vivo. Am J Pathol 1990;136:1125-35. 11. Koehler JE, Quinn FD, Berger TG, et al. Isolation of Rochalimaea species from cutaneous and osseous lesions of bacillary angiomatosis. N Engl J Med 1992;327:162531.

12. Brenner DJ, O'Connor SP, Winkler HH, et al. Proposals to unify the genera Bartonella and Rochalimaea, with descriptions of Bartonella quintana comb. nov., Bartonella vinsonii comb. nov., Bartonella henselae comb. nov., and Bartonella elizabethae comb. nov., and to remove the family Bartonellaceae from the order Rickettsiales. Int J Syst Bacteriol 1993;43:777-86.

13. Brenner DJ, Hollis DG, Moss CW, et al. Proposal of Afipia gen. nov., with Afipia felis sp. nov. (formerly the cat scratch disease bacillus). Afipia clevelandensis sp. nov. (formerly the Cleveland Clinic Foundation strain), Afipia broomeae sp. nov., and three unnamed genospecies. J Clinic Microbiol 1991;29:2450-60.

14. Baron AL, Steinbach LS, LeBoit PE, et al. Osteolytic lesions and bacillary angiomatosis in HIV infection: radiologic differentiation from AIDS-related Kaposi sarcoma. Radiology 1990:177;77-81.

15. Perkocha LA, Geaghan SM, Yen TSB, et al. Clinical and pathological features of bacillary peliosis hepatis in association with human immunodeficiency virus infection. $\mathrm{N}$ Engl J Med 1990;323:1581-6.

16. Slater LN, Welch DF, Hensel D, et al. A newly recognized fastidious gram-negative pathogen as a cause of fever and bacteremia. N Engl J Med 1990;323:1587-93.

17. Regnery RL, Anderson BE, Clarridge JE III, et al. Characterization of a novel Rochalimaea species, $R$. henselae, sp. nov., isolated from blood of a febrile, HIVpositive patient. J Clin Microbiol 1992;30:265-74.

18. Szych CM, Rotter SM, Gallant JE. Papules and nodules in a patient with the acquired immunodeficiency syndrome and recurrent cryptococcal meningitis. Arch Dermatol 1992;127:1832-3,1835-6.

19. LeBoit PE. Bacillary angiomatosis: a systemic opportunistic infection with prominent cutaneous manifestation. Semin Dermatol 1991:10:194-8.

20. Reed JA, Brigati DJ, Flynn SD, et al. Immunocytochemical identification of Rochalimaea henselae bacillary (epithelioid) angiomatosis, parenchymal bacillary peliosis, and persistent fever with bacteremia. Am J Surg Pathol 1992;16:650-7. 21. Regnery RL, Olson JG, Perkins BA, et al. Serological response to Rochalimaea henselae antigen in suspected cat-scratch disease. Lancet 1992;339:1443-5. 22. Patnaik M, Schwartzman WA, Barka NE, et al. Possible role of Rochalimaea henselae in pathogenesis of AIDS encephalopathy (letter). Lancet 1992;340:971. 23. Relman DA, Loutit JS, Schmidt TM, et al. The agent of bacillary angiomatosis: an approach to the identification of uncultured pathogens. N Engl J Med 1990;323:1573-80. 24. Spach, DM. Bacillary angiomatosis. Intern J Dermatol 1992;31;19-24. 


\section{Lipa et al}

\section{Bacillary angiomatosis}

25. Koehler JE, LeBoit PE, Egbert BM, et al. Cutaneous vascular lesions and disseminated cat-scratch disease in patients with acquired immuno-deficiency syndrome (AIDS) and AIDS-related complex. Ann Intern Med 1988;109:449-55.

26. Berger TG, Koehler JE. Bacillary angiomatosis. In: Volberding P, Jacobson MA, eds. AIDS Clinical Review 1993. New York: Marcell Dekker, 1993.

27. Cockerell CJ, Whitlow MA, Webster GF, et al. Epithelioid angiomatosis: a distinct vascular disorder in patients with acquired immunodeficiency syndrome or AIDS-related complex. Lancet 1987;ii:654-6.

28. Tappero JW, Mohle-Boetani J, Koehler JE, et al. The epidemiology of bacillary angiomatosis and bacillary peliosis. JAMA 1993;269:770-5. 